\title{
Demand Side Management in Pellet Production: Internal and External Factors
}

\author{
Haralds Vigants ${ }^{1}$, Dagnija Blumberga ${ }^{2}$, Ivars Veidenbergs ${ }^{3},{ }^{1-3}$ Riga Technical University
}

\begin{abstract}
This paper demonstrates a demand side management case study: how to save energy and how research and data analysis help to create an energy management system in a pellet production facility; and shows ways to implement the $\mathbf{E U}$ energy efficiency directive in production facilities. The study carried out in this research serves as a far-reaching step that can be taken to improve energy efficiency during the operation mode of technological equipment. The benchmarking methodology is used for analysis of results.

Internal and external factors and indicators, which affect energy management potential in pellet production are analysed. Analysis of external factors is based on the state legal framework regulating the development of the energy sector. Methodology on the analysis of energy demand includes the internal energy management of an enterprise. The experimental results discussed in this paper show that particular steps, which are oriented to specific use of technological equipment, could play significant
\end{abstract}

role in energy efficiency improvement in industry which is illustrated by the pre-milling process in the pellet production system using power.

Keywords - Demand side management, pellet production, energy efficiency, energy savings.

\section{INTRODUCTION}

Production of wood pellets in the Baltic countries has been growing as new large- and small-scale facilities emerge. It is crucial that these industries are energy efficient and employ innovative approaches in saving resources. One of the corresponding measures is energy management. Energy management in pellet industries is important for a number of reasons:

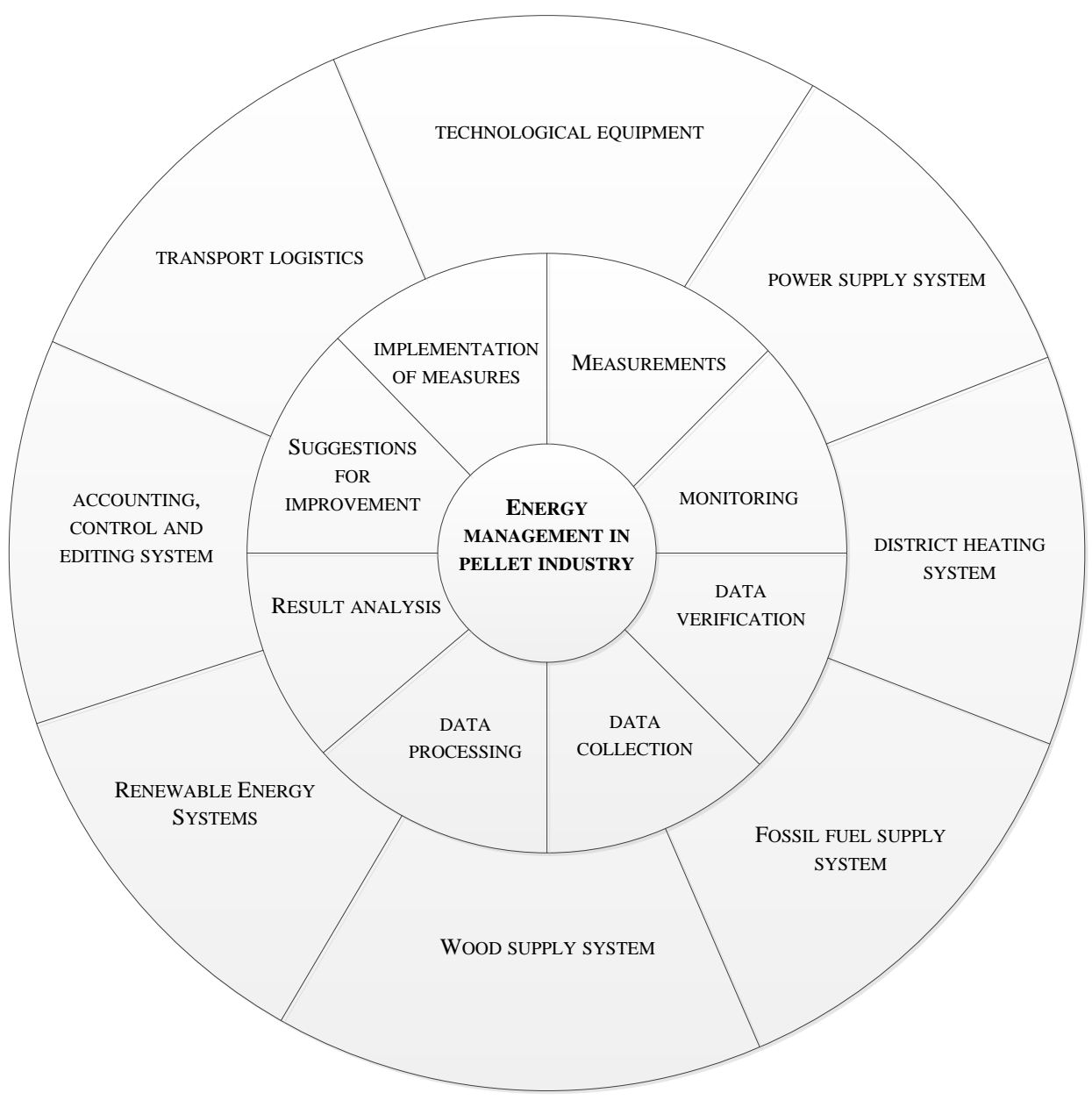

Fig. 1. Demand side management scheme with internal and external factors. 
- Efficient energy production and use is the most significant sector for development in EU countries;

- The new international framework ISO 50001:2011 has been developed for creating an energy management system. Its integration and implementation in enterprises could facilitate the shift to a low carbon society;

- Energy management in an enterprise allows saving both energy and financial resources.

Reduction of energy consumption in the pellet industries is possible at different levels: internal energy management of an enterprise - the measures implemented within the industry; and assessment of the effects of external factors - national economy sectors, the development of which affects the sustainability of pellet industries. Fig. 1 illustrates the corresponding internal and external factors.

Analysis of energy demand is based on the internal energy management of an enterprise:

- Through monitoring of the parameters of an enterprise's activity;

- Development, selection and implementation of energy management enhancing measures - according to the ISO 50001:2011 standard.

One of the most significant steps in energy management is analysis of the results obtained after collection and processing of data on the current situation within an enterprise. Fig. 2 shows an example of testing, which is an important part of any enterprise's activities.

Analysis of external factors is based on the state legal framework regulating development of the energy sector:

- Development of the pellet market, which creates added value to the local resource - biomass,

- Replacement of fossil fuel due to the economic and climate change aspects,

- Use of renewable energy sources employing innovative technological solutions,

- Development of transport logistics reducing the mileage of empty transport: for instance, the shortterm problems for pellet industries created by the Russian embargo [1], as ships carrying pellets to Latvia are coming half-empty.

- Considering the economic situation in countries with well-developed forestry industry: for instance, raw material import from Russia to Latvia is more beneficial when the value of the Russian Rouble currency dropped.

One of the most significant steps of energy management is analysis of the results obtained after collection and processing of data [2-5]. Fig. 2 shows an example of testing, which is an important part of an enterprise's activities. The study shows how a pellet plant can benefit or lose when the production scheme is changed (pre-milling before standard milling process is introduced). The author of the paper has shown that the changed traditional production scheme has a positive effect on efficiency and profit [7]. Authors of [8-19] have analysed results of methodologies' use to implement the industrial factories [8-11] and the industry demand side management (DSM) for energy use [12-19].

The results of DSM activities in pellet production allow to find technologies with highest energy intensity according to pellets high quality [20], [21]. The article will look at the possibilities to change the production scheme within the framework of the energy management system in order to reduce the consumption of electricity by the production facilities.

\section{METHODOLOGY}

\section{A. Initial Operational Scheme of the Pellet Production Facility}

For the production of wood pellets, 4 main raw material flows can be distinguished: wood chips, sawdust, bark and branch chips, see Fig. 2 .

Humid sawdust, $40 \%-50 \%$ of moisture content, is the basic material for production of wood pellets. Only clean sawdust can be used for production. Sawdust may not contain any impurities: it has to be dried, free of any sand, abrasive particles and chemical compounds.

After additional pre-processing, cellulose fiber and technological wood chips can also be used to produce pellets. Pre-processing of wood chips takes place in a special cutting device, see Flacker in Fig. 2. The system of the cutter consists of a range of electrical machines like chippers, peelers, conveyors, ventilators, hydro devices and others.

Another stream of raw materials is used as fuel in pellet production facility; these are branch chips and bark. They are combusted for production of flue gases and for energy production in the cogeneration plant (CHP) (see Flue gas generation and CHP in Fig. 2).

The furnace system in the flue gas production consists of several electrical motors that power equipment for ensuring the operation of the furnace, i.e. heating, cooling, feeding of fuel, ventilators, valves and hydro machinery. Produced flue gases are fed to the drum dryer.

Heat from the CHP is transferred to belt-type dryers (see produced heat flow in Fig. 2), where sawdust is dried until the required humidity level for production of wood pellets. The largest consumers of electricity for the belt dryer are the ventilators which suck heated air through sawdust.

Dried sawdust material is dosed to a hammer mill where sawdust is crushed. During the milling process, dried sawdust is turned into small, less than $3.15 \mathrm{~mm}$, particles and dust, and a uniform substance is obtained. The milling system consists of several electrical motors that power the equipment for ensuring the milling of sawdust, i.e. heating, cooling, a dosing device, ventilator, worm-type transporter, mill and hydro machinery.

Next are the presses, there is a process during which the mix of sawdust is delivered into two pressing rolls and a rotating matrix. The process results in the production of hot pellets with a diameter of $8 \mathrm{~mm}$. The granulating system consists of several electrical motors that power the equipment, 


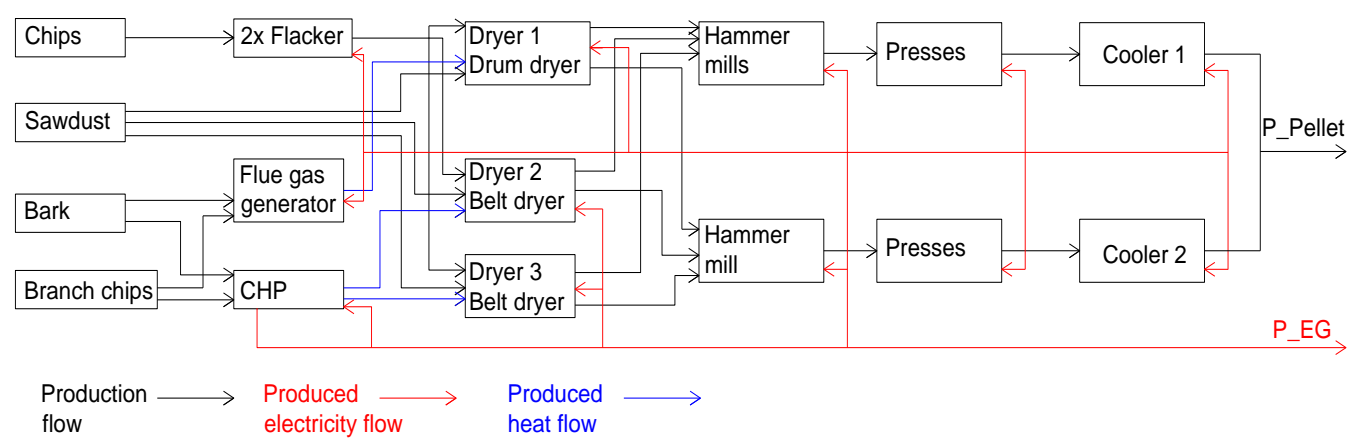

Fig. 2. Initial operational scheme of the pellet production facility [3].

i.e. conveyors, suction devices, coolers, worm-type transporters, a vibrant-screen, dosing devices, a mixer, a central lubricating system and presses.

Granulation is followed by cooling and screening where pellets become hard and are clean from any dust. This final production process - pellets are ready for storage and transportation.

\section{B. Modified Operational Scheme of the Pellet Production Facility}

For dry sawdust milling, hammer mills are commonly used with two outcomes: production of pellets (P_Pellets) and generation of electrical power (P_EG) (see Fig. 2 and 4). The principle scheme of hammer mill used is shown in Fig. 3A. This mill operates by the following principle: firstly, sawdust is smashed by $4 \mathrm{~mm}-8 \mathrm{~mm}$ plates or hammers rotating around their own axis, secondly, the smashed sawdust is squeezed through screens with $5 \mathrm{~mm}-20 \mathrm{~mm}$ large openings.

The modified operational scheme looks at an option when, in addition to the regular milling process, pre-milling is introduced. In the case of pre-milling, larger screens are placed in the first mill (shown schematically in Fig. 3B), leaving standard screens in the second mill, which are

necessary to ensure the quality of the products accordingly to the LVS EN 16126:2012 [4].

By introducing the pre-milling process, the modified operational scheme is obtained (see Fig. 4).

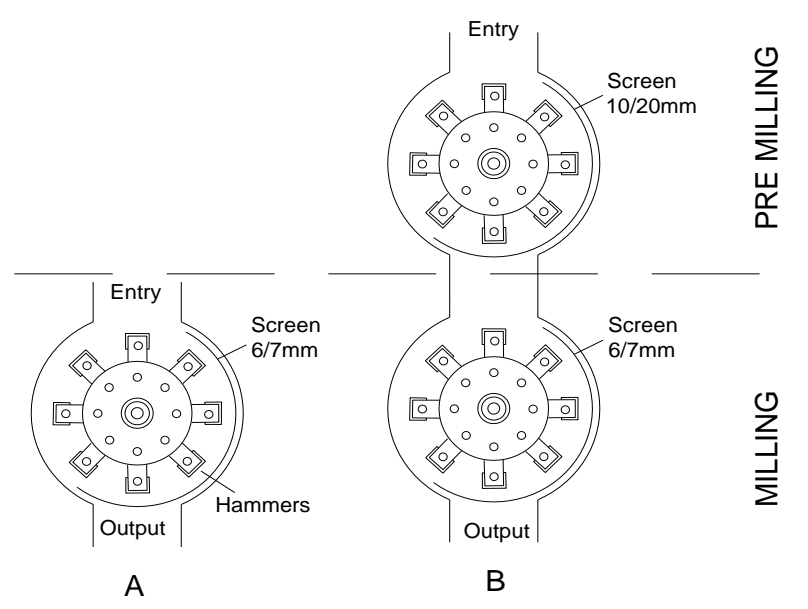

Fig. 3. Hammer mill principle scheme.

\section{Assessment of Proposed Modifications}

To evaluate the influence of proposed modifications various measurements were carried out at the company for both initial and modified operation scheme. These measurements included the amount of milled product, electrical energy consumed for pre-milling and milling processes and the amount of time needed for pre-milling and milling processes.

In order to obtain comparable results, the measurements where stopped when the amount of milled produced reached $10.5 \mathrm{t}$.

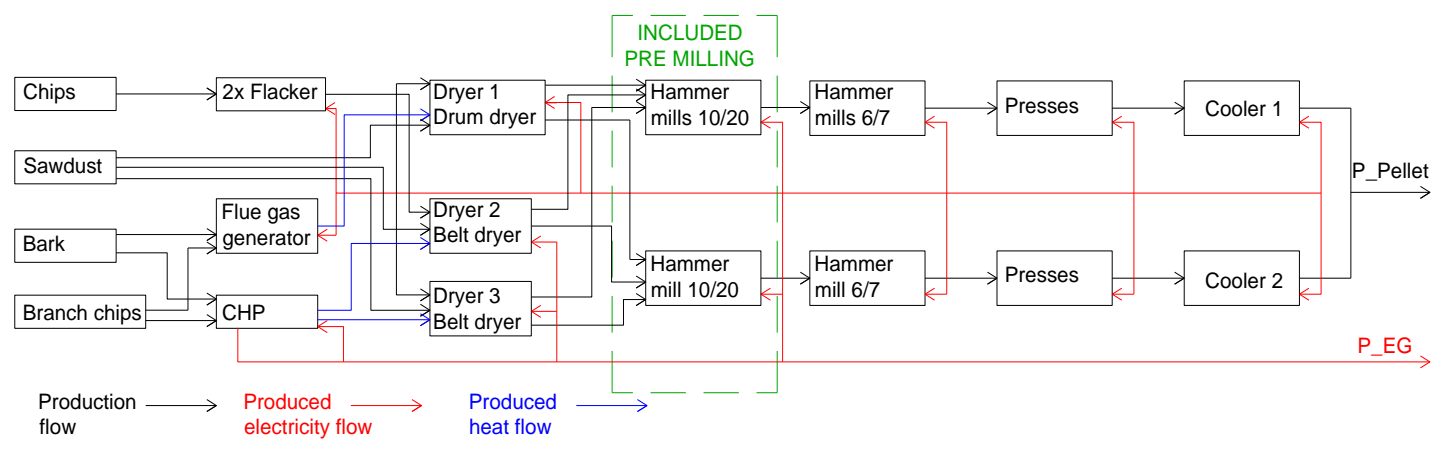

Fig. 4. Modified operational scheme of the pellet production facility with pre-milling. 
In the first round of measurements the milling process of the initial operation scheme was evaluated. The hammer mill operated in the milling mode, two screens were placed in the mill with openings of one screen being $6 \mathrm{~mm}$ in diameter, and of the other screen $-7 \mathrm{~mm}$ in diameter (see Fig. 3A). In the milling mode the mill processed the material which was not previously used in the pre-milling process (see Fig. 4).

In the second round of measurements the pre-milling process of the modified operational scheme was evaluated. The hammer mill operated in pre-milling mode, two screens were placed in the mill with openings of one screen being 10 $\mathrm{mm}$ in diameter, and of the other screen $-20 \mathrm{~mm}$ in diameter (see Fig. 3B).

In the third round of measurements the milling process of the modified operational scheme was evaluated. The hammer mill operated in milling mode, two screens were placed in the mill with openings of one screen being $6 \mathrm{~mm}$ in diameter, and of the other screen $-7 \mathrm{~mm}$ in diameter (see Fig. 3B). In the milling mode the mill processed the material obtained in the pre-milling process (see Fig. 4).

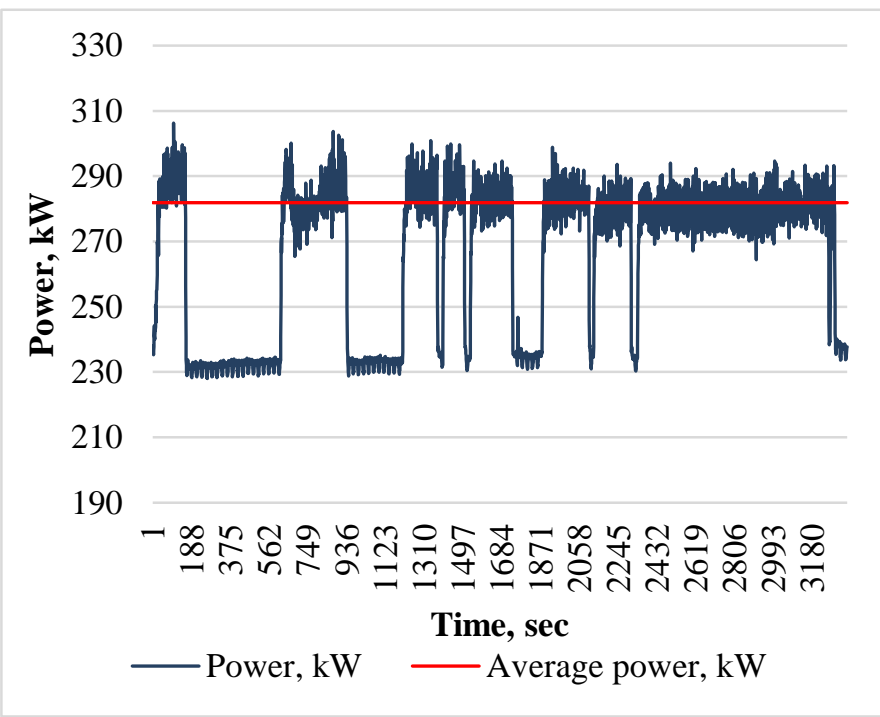

Fig. 5. Electric power in pre-milling mode for modified operation scheme.

It took less time to produce $10.5 \mathrm{t}$ to milled sawdust when pre-milling and milling processes in the modified operation scheme are analysed separately. Nevertheless for the total modified operation scheme (pre-milling and milling summed up) the specific time consumption was higher than for the initial scheme, see Table I.
After the measurements the data was processed to obtain 2 indicators: specific time consumption, expressed as hours needed for production of 1 tonne of milled sawdust, and specific electricity consumption, expressed as kWh needed for production of 1 tonne of milled sawdust.

\section{RESUlTS AND DISCUSSION}

The measurements for the initial operation schemes showed that 10.5 tonnes of milled sawdust were produced within 42 minutes see Table I. The average electric power of the electric motor was $480 \mathrm{~kW}$. These results will be used as benchmarks for the comparison with the modified operation scheme.

The measurement for the modified operation scheme showed that the mills where not feed eventually, since the mill productivity was higher than expected. Therefore, for further data processing, the data points above the engine power of $250 \mathrm{~kW}$ were considered (see Fig. 5 and 6).

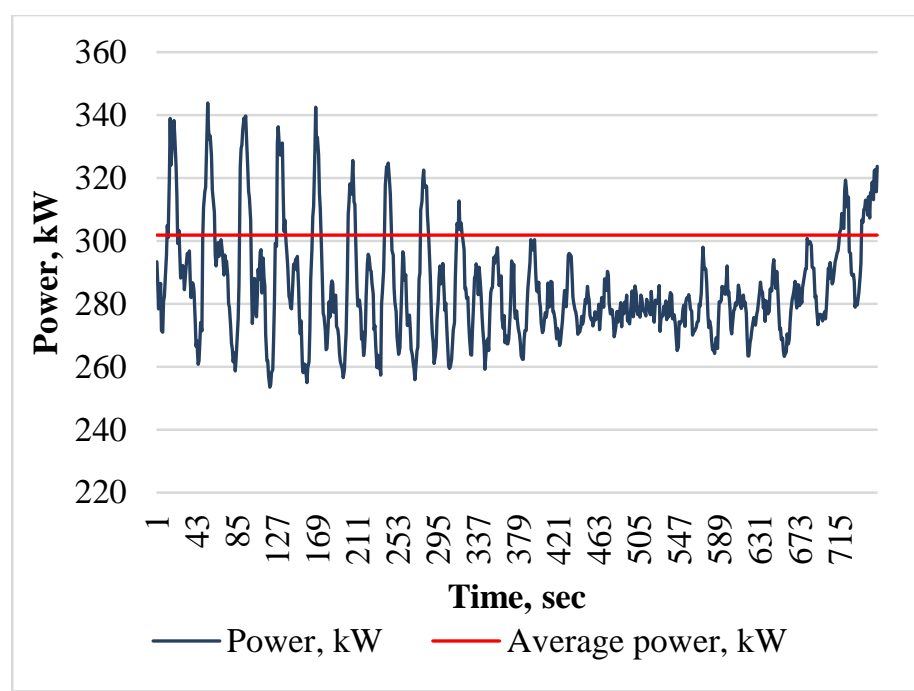

Fig. 6. Electric power in the milling mode (processing the material obtained in the pre-milling process) for modified operation scheme.

In the modified operation conditions the total power of two mills (pre-milling and milling after pre-milling) is larger than the power of one mill in the initial operation scheme. At the same time the reduction of $29 \%$ in specific electricity consumption was achieved by pre-milling introduction, see Table I.

TABLE I

RESUlts OF PROPOSED MODIFICATIONS AND THE COMPARISON OF INITIAL AND MODIFIED OPERATION SCHEME

\begin{tabular}{|c|c|c|c|c|c|}
\hline & Test name & $\begin{array}{l}\text { Duration of the } \\
\text { test }^{*}, h\end{array}$ & $\begin{array}{c}\text { Average electricity } \\
\text { power, } k W\end{array}$ & $\begin{array}{c}\text { Specific time } \\
\text { consumption, h/t }\end{array}$ & $\begin{array}{l}\text { Specific electricity } \\
\text { consumption, } k W h / t\end{array}$ \\
\hline Initial operation scheme & Milling without pre-milling & 0.70 & 480.00 & 0.067 & 32.00 \\
\hline \multirow[t]{3}{*}{ Modified operation scheme } & Milling with pre-milling & 0.84 & 283.52 & 0.080 & 22.61 \\
\hline & Pre-milling & 0.64 & 281.88 & 0.061 & 17.18 \\
\hline & Milling after pre-milling & 0.20 & 285.16 & 0.019 & 5.43 \\
\hline \multicolumn{2}{|c|}{ Difference between initial and modified operation scheme } & $+20 \%$ & $-41 \%$ & $+19 \%$ & $-29 \%$ \\
\hline
\end{tabular}

\footnotetext{
* In order to obtain comparable results, the measurements where stopped when the amount of milled produced reached 10.5 tonnes.
} 
Increased specific time need but decreased specific electricity consumption can be explained by the fact that in the modified operation conditions mills where operating at lower and fluctuating power demand (see Fig. 5 and 6). In the modified operational schemes it can be argued that the different roughness hammer mills working in a row where able to perform the smashing of sawdust more effectively than

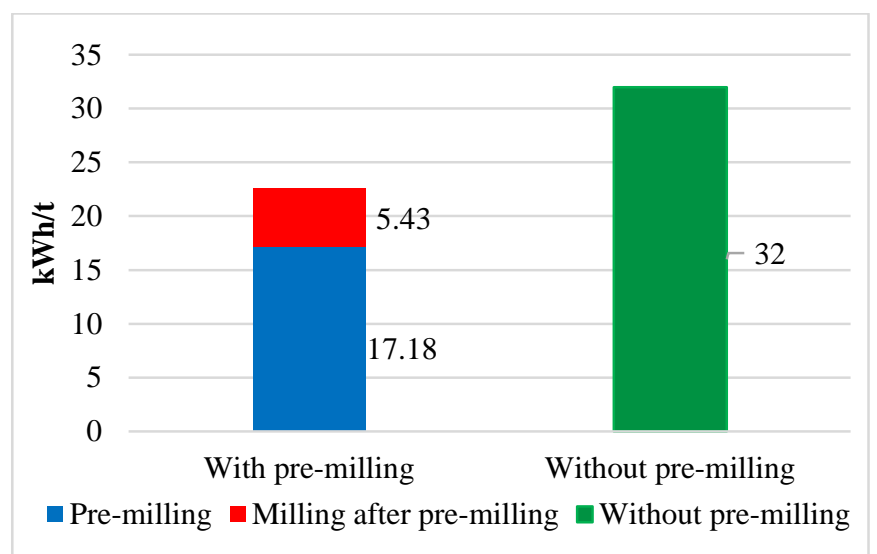

Fig. 7. Specific electricity consumption by milling mode.

Using the pre-milling process, the time needed to produce one tonne of production decreases by 0.006 hours per tonne, compared to the production process scheme when pre-milling is not used.

If a production facility produces about 16000 tonnes of products monthly, then on a monthly basis, time saving would account for approximately 95 hours, which can be used to carry out preventive maintenance of the production facility or for increasing production volumes. Production facility electricity savings per month would account for $150000 \mathrm{kWh}$.

\section{CONCLUSION}

This research paper demonstrates how research and data analysis help creating an energy management system in a pellet production facility, as well as help improving the energy efficiency of production facilities. The study carried out serves as a far-reaching step that can be taken to improve energy efficiency during operation mode of technological equipment. The previous related publications focused on optimisation of power consumption, optimisation of thermal load, and optimisation of energy costs. This work, in turn, shows an opportunity how to increase the efficiency of production facilities by introducing new equipment. This paper may be taken as an example to be used in the energy management of a production facility. The benchmarking methodology is used for analysis of results.

The experiments discussed in this paper show that, upon introduction of the pre-milling process in the pellet production system using the same electrical power, the electric efficiency does not improve, because after pre-milling, the production rate in the mill is approximately three times greater than if the same mill is used for pre-milling. Examining the pre-milling and milling process jointly, when the material obtained in pre- the same roughness hammer mills in a parallel configuration (initial operation scheme).

Fig. 7 gives visual comparison on the specific electricity consumption per tonne milled sawdust for each operational mode. The specific electricity consumption is reduced by $9.39 \mathrm{kWh}$ per tonne of product obtained in our case study.

Efficiency indicators are shown in Fig. 8.

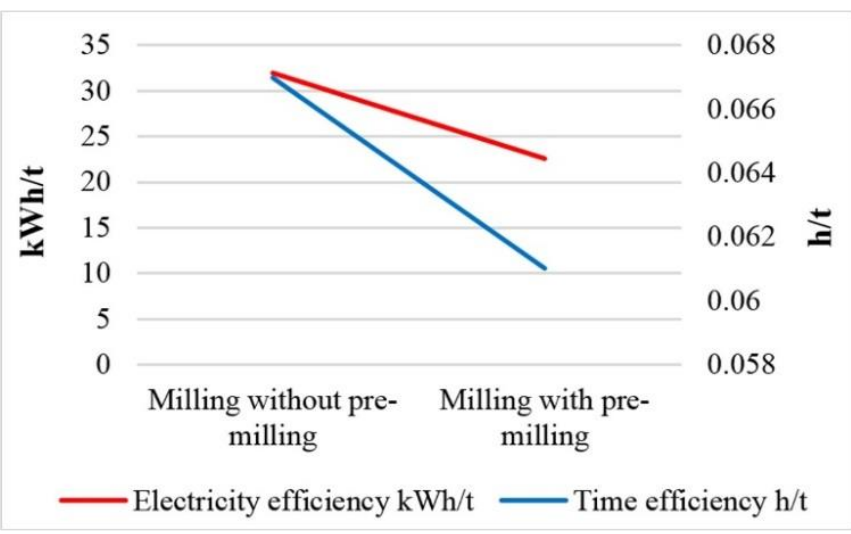

Fig. 8. Electricity and time efficiency comparisons in operational mode with and without the pre-milling process.

milling is re-ground, it can be concluded that electricity efficiency pre one tonne in this mode is higher than in cases when pre-milling is not used. In the case analysed in this article, the saving accounts for $9.39 \mathrm{kWh} / \mathrm{t}$.

It is possible to speed up the production cycle by introducing pre-milling in the production scheme due to the large openings of the screens, less time needs to be consumed in pre-milling to mill the same amount of raw material. After pre-milling, the time in the mill compared to production without pre-milling decreases three times.

The pellet production facility operation can be improved by the pre-milling process. Examining the option when we want to improve an existing production facility, it is necessary to evaluate the existing facility abilities and the option to raise production capacity.

The least effect on the operation of an existing facility would be in case another mill were to be installed after the already existing mill, and thus the existing mill would be used for the pre-milling function. The new mill should be chosen with an approximately three times lower productivity rate than of those used in pre-milling, because the tests carried out showed that productivity of the mill increased three times if it is fed with pre-milled material. In order to ensure a more even power consumption, it is necessary to create funnels above the two mills to accumulate the material for a short period of time.

By introducing pre-milling in the production process, it should be taken into account that there will be a new equipment introduced that will need to be maintained on a regular basis and which may have unexpected downtime. It should be also noted that upon installing a pre-milling mill, the air flows will change. Therefore the air extraction system will need to be modified, which also requires an additional investment. 


\section{REFERENCES}

1. Information Note on the Russian Ban on Agri-food Products from the $E U$, European Comission, 2014. 19 p. Available: http://ec.europa.eu/ agriculture/russian-import-ban/pdf/info-note-03-09_en.pdf [Accessed: 25.09.2014.]

2. Kalnins, S. N., Valtere, S., Gusca, J., Blumberga, D. Combined management response and indicator based evaluation methodology of implementation of environmental management system at a wood production industry. Agronomy Research, 2014, vol. 12, No. 2, pp. 479-490.

3. Vigants, H., Uuemaa, P., Veidenbergs, I., Blumberga, D. Cleaner pellet production. Energy consumption study using statistical analysis, Agronomy Research, 2014, vol. 12, No. 2, pp. 633-644.

4. Uuemaa, P., Vigants, H., Blumberga, D., Drovtar, I. Industrial CHP excess heat efficient usage for cooling, Energetika, 2014, vol. 60, No. 2, pp. 136-148. http://dx.doi.org/10.6001/energetika.v60i2.2937

5. Uuemaa, P., Drovtar, I., Kilter, J., Vigants, H., Blumberga, D., Puusepp, A. Industrial CHP Optimal Management in the Energy Market under Incomplete Information. In: Innovative Smart Grid Technologies Asia (ISGT ASIA), Kuala Lumpur, Malaysia, 2014.

http://dx.doi.org/10.1109/ISGT-Asia.2014.6873822

6. Xiang-ting, C., Yu-hui, Z., Wei, D., Jie-bin, T., Yu-xiao, G. Design of intelligent Demand Side Management System Respond to Varieties of Factors. In: China International Conference on Electricity Distribution, Nanjing, China, 2010.

7. Inamdar, H. P., Hasabe, R. P. It based energy management through demand side in the industrial sector. In: International Conference on Control, Automation, Communication and Energy Conservation (INCACEC), Perundurai, India, 2009.

8. Mobini, M., Meyer, J. C., Trippe, F., Sowlati, T., Fröhling, M. Schultmann, F. Assessing the integration of torrefaction into wood pellet production. Journal of Cleaner Production, 2014, No. 78, pp. 216-225. http://dx.doi.org/10.1016/j.jclepro.2014.04.071

9. Caihong, C., Yongqiang, Z., Yu, X., Distributed Generation and Demand Side Management. In: China International Conference on Electricity Distribution, Nanjing, China, 2010.

10. Palma-Behnke, R., Benavides, C., Aranda, E., Llanos, J., Siez, D. Energy Management System for a Renewable based Microgrid with a Demand Side Management Mechanism. In: IEEE Symposium on Computational Intelligence Applications In Smart Grid (CIASG), Paris, France, April 11-15, 2011, pp. 1-8. http://dx.doi.org/10.1109/CIASG.2011.5953338

11. Huibin, S., Ying, S., Wei-Jen, L., Huibin, S., Ying, S., Wei-Jen, L. A Demand Side Management Model Based on Advanced Metering Infrastructure. In: 4th International Conference on Electric Utility Deregulation and Restructuring and Power Technologies (DRPT), Weihai, China, July 6-9, 2011, pp. 1586-1589. http://dx.doi.org/10.1109/DRPT.2011.5994150

12. Yang, L., Deuse, J., Droste, M. Energy Efficiency at Energy Intensive Factory - A Facility Planning Approach. In: IEEE 18Th International Conference on Industrial Engineering and Engineering Management (IE\&EM), Changchun, China, September 3-5, 2011, pp. 699-703. http://dx.doi.org/10.1109/ICIEEM.2011.6035252

13. Drovtar, I., Uuemaa, P., Rosin, A., Kilter, J., Valtin, J. Using Demand Side Management in Energy - Intensive Industries for Providing Balancing Power - the Estonian Case Study. In: IEEE Power and Energy Society General Meeting (PES), Vancouver, Canada, July 21-25, 2013, pp. 1-5. http://dx.doi.org/10.1109/PESMG.2013.6672418

14. Gu, W., Wu, Z., Bo, R., Liu, W., Zhou, G., Chen, W., Wu, Z. Modeling, planning and optimal energy management of combined cooling, heating and power microgrid: A review. Electrical Power and Energy Systems, 2014, vol. 54, pp. 26-37 http://dx.doi.org/10.1016/i.ijepes.2013.06.028

15. Introna, V., Cesarotti, V., Benedetti, M., Biagiotti, S., Rotunno, R. Energy Management Maturity Model: an organizational tool to Foster the continuous reduction of energy consumption in companies. Journal of Cleaner Production, 2014, vol. 83, pp. 108-117. http://dx.doi.org/10.1016/j.jclepro.2014.07.001

16. Pantaleo, A., Candelise, C., Bauen, A., Shah, N. ESCO busines models for biomass heating and CHP: Profitability of ESCO operations in Italy and key factors assessment. Renewable and Sustainable Energy Reviews, 2014, vol. 30, pp. 237-253. http://dx.doi.org/10.1016/j.rser.2013.10.001
17. Suhonen, N., Okkonen, L. The Energy Services Company (ESCo) as business model for heat entrepreneurship-A case study of North Karelia, Finland. Energy Policy, 2013, vol. 61, pp. 783-787. http://dx.doi.org/10.1016/j.enpol.2013.06.047

18. Dörr, M., Wahren, S., Bauernhansl, T. Methodology for energy efficiency on process level, In: Forty Sixth CIRP Conference on Manufacturing Systems. Setubal, Portugal, May 29-30, 2013. Procedia CIRP, vol. 7, pp. 652-657. http://dx.doi.org/10.1016/j.procir.2013.06.048

19. Selivanovs, J., Blumberga, D., Ziemele, J., Blumberga, A., Barisa, A. Research of Woody BiomassDrying process in Pellet Production. Journal of Environmental and Climate Technologies, 2012, vol. 10, pp. 46-50. http://dx.doi.org/10.2478/v10145-012-0017-7

20. Kirsanovs, V., Timma, L., Zandeckis, A., Romagnoli, F. The Quality of Pellets Available on the Market in Latvia: Classification According EN14961 Requirements. Journal of Environmental and Climate Technologies, 2012, vol. 8, pp. 36-40. http://dx.doi.org/10.2478/v10145-012-0006-X

21. Cietās biodegvielas. Sadrupinātu granulu granulometriskā sastāva noteikšana LVS EN 16126:2012

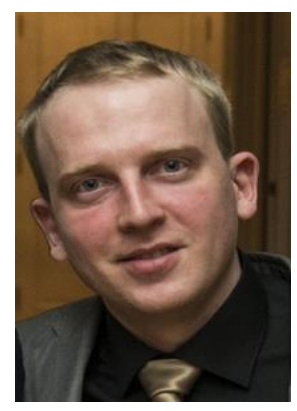

Haralds Vigants, Mg. sc. ing., third year $\mathrm{PhD}$ student of Environmental Engineering study programme in Institute of Energy Systems and Environment, Faculty of Power and Electrotechnics, Riga Technical University. He has two steps master degree diploma. Master's thesis "Choice and substantiation of primary scheme of $300 \mathrm{kV}$ substation." was defended in Faculty of Energy and Electronics, Riga Technical University (2009). Master's thesis „Energy consumption prediction of wood pellet plant with an unstable power consumption" was defended in Faculty of Energy and Electronics, Riga Technical University (2011). The main research area is energy and environment. E-mail: haralds.vigants@rtu.lv

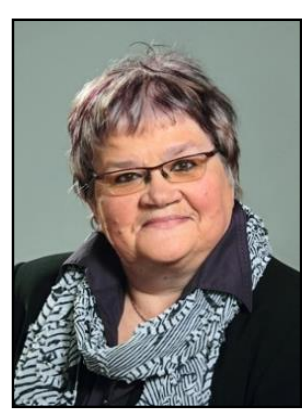

Dagnija Blumberga, Dr. habil. sc. ing., professor at the Riga Technical University, Institute of Energy Systems and Environment. She has Thermal Engineer Diploma (1970). Doctoral degree was defended in Lithuanian Energy Institute, Kaunas (1988). Doctor Habilitus Thesis "Analysis of Energy Efficiency from Environmental, Economical and Management Aspects" was prepared in Royal Institute of Technology (KTH) Stockholm (1995) and was defended in Faculty of Energy and Electronics, Riga Technical University (1996). Professor Dagnija Blumberga has been part of academic staff of Faculty of Energy and Electrotechnics, Riga Technical University since 1976 and director of Institute of Environmental Protection and Energy Systems since 1999. The main research area is renewable energy resources, heating systems and climate technologies. She has participated in different local and international projects related to climate change, energy and environment as well as is author of more than 200 publications and 15 books.

E-mail: dagnija.blumberga@rtu.lv

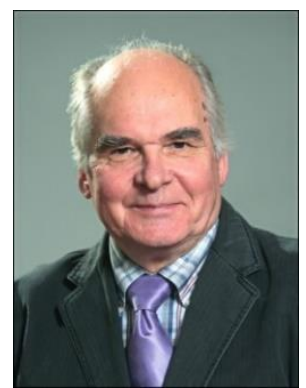

Ivars Veidenbergs, Dr. habil. sc. ing., professor at the Riga Technical University, Institute of Energy Systems and Environment. He has thermal engineer diploma (1960) in speciality "Thermal equipment of thermal power stations" and two steps doctoral degree diploma, $\mathrm{PhD}$ thesis "Dynamic Temperature Regimes of Thermoelectric Cooling Devices" was defended in Riga Polytechnic Institute (1975). Doctor Habilitus Thesis "Engineering Methods for Calculating Hear and Mass Transfer in the devices of Power Units" was defended in Faculty of Energy and Electronics, Riga Technical University (1992). The main research area is energy and environment. He is the author of more than 180 publications and 5 books.

E-mail: ivars.veidenbergs@rtu.lv 